\title{
A Decision Support System for Efficient Last-Mile Distribution of Fresh Fruits and Vegetables as Part of E-Grocery Operations
}

\author{
Martin Waitz \\ WU Vienna University of \\ Economics and Business, \\ Department of Information \\ Systems and Operations, \\ Institute for Production \\ Management \\ $\underline{\text { martin.waitz@wu.ac.at }}$
}

\author{
Andreas Mild \\ WU Vienna University of \\ Economics and Business, \\ Department of Information \\ Systems and Operations, \\ Institute for Production \\ Management \\ andreas.mild@wu.ac.at
}

\author{
Christian Fikar \\ University of Natural Resources \\ and Life Sciences, Vienna, \\ Institute of Production and \\ Logistics \\ christian.fikar@boku.ac.at
}

\begin{abstract}
Efficient last-mile distribution of fresh fruits and vegetables is a major challenge within e-grocery operations. This work presents a decision support system to jointly investigate the impact of various service offers on customer preferences and logistics operations. Results from a conjoint analysis surveying 531 end consumer are incorporated within an agentbased simulation. Delivery days, fees, time windows and discounts as well as guaranteed remaining shelf life of products at delivery are considered. To model shelf life and schedule deliveries, food quality models and vehicle routing procedures are further integrated within the system. Based on an e-grocery provider operating in Vienna, Austria, computational experiments investigate the impact of the offered delivery service on fulfilled demand, order volume and customer utility. Results indicate the importance of incorporating shelf life data within e-grocery operations and various potentials of considering customer preferences in logistics decision support systems.
\end{abstract}

\section{Introduction}

Both the demand for e-groceries [1], i.e. buying food products online, and fresh fruits and vegetables (FFVs) [2] are expected to increase significantly. The last-mile distribution of such products, however, is challenging, particularly in an e-fulfillment context. In addition to optimizing distribution costs to stay competitive, various food-related factors such as food safety, cold chains and remaining shelf life have to be considered within food logistics operations [3]. Particularly, shelf lives of FFVs are greatly impacted by the specific temperatures during storage, handling and transport operations within the food supply chain [4]. In most cases, shelf lives further have a direct impact on both product value and the generation of food waste. For instance, strawberries have a postharvest shelf life of five to seven days considering perfect storage and handling conditions [5].

To assist operations, this work investigates the impact of incorporating remaining shelf lives of FFVs within e-grocery operations. Assuming that customers mainly prefer products with long remaining shelf lives, providers may increase sales by guaranteeing customers specific quality levels at delivery. Such a strategy, however, impacts the logistics operations of the provider, requiring an integrated investigation of offered services, product selection and vehicle routing operations. To enable decision-makers to make such investigations and to assist in the design of e-grocery distribution concepts for FFVs, a decision support system (DSS) is presented. It combines food quality models and vehicle routing procedures within an agentbased simulation. Furthermore, findings derived from a conjoint analysis of customers in Vienna, Austria, are incorporated. The contribution of this work is twofold: (i) it provides guidelines on how to integrate customer data derived from a conjoint analysis in a logistics DSS, and (ii) presents case of usage to investigate different service offers within e-grocery operations based on remaining shelf lives of FFVs.

The remainder of this work is structured as follows: Related work is introduced in Section 2. The problem setting is described in Section 3, while Section 4 presents the performed conjoint analysis. In Section 5, the developed DSS is introduced. Section 6 introduces the performed computational experiments and Section 7 discusses preliminary results. Concluding remarks are given in Section 8. 


\section{Related Work}

In literature, e-fulfillment and last-mile distribution of e-groceries are studied from various perspectives. A general overview on e-fulfillment and multi-channel distribution is given in [6]. [7] focus on omni-channel grocery retailing and present a framework to classify last-mile distribution concepts for e-groceries based on picking strategy, delivery mode, delivery time, delivery area and how returns are handled.

Recent work on food logistics operations is reviewed in [3]. Various research topics requiring further attention are listed including a closer investigation of the impact of various distribution strategies on product characteristics such as value, perishability, and shelf life. Additionally, in a review of operations research models for FFVs supply chains, [8] note that more work focusing on uncertainties present in food operations is required.

Assuming a store-based delivery of e-groceries, the corresponding vehicle routing problem can be classified as an extended pickup and delivery problem. For a survey on recent work in this field, refer to [9]. For food logistics operations, multiple work extends the problem by adding food-specific constraints such as heterogeneous vehicles [10] or temperature control [11]. In [12], a metaheuristic solution procedure to route e-grocery deliveries is developed. The authors distinguish between regular and premium customers. The former order regular products available at a central location, while the latter order both regular and premium products. Premium products are located at external vendors, resulting in additional pickup locations which have to be visited before serving a premium customers. Perishability or food quality is not explicitly considered.

Consequently, while various work has been done in related fields, a closer investigation of incorporating customer preferences and offering customers guaranteed shelf lives of FFVs at delivery is required.

\section{Problem Description}

The setting of an e-grocery provider operating multiple stores within an urban area is considered. Based on the classification presented in [2], the main characteristics of the considered e-grocery fulfillment system are given Table 1. It considers in-store picking and an attended home delivery concept within a time slot requested by the customer. No return shipments are modeled within the studied problem setting. The provider's objective is to minimize travel distances while respecting customer specifications concerning delivery times and guaranteed shelf lives.
Table 1. Classification of the considered problem setting

\begin{tabular}{|c|c|}
\hline Parameter & Descrintion \\
\hline Picking & $\begin{array}{l}\text { Manual, in-store picking } \\
\text { separated from regular store } \\
\text { operations }\end{array}$ \\
\hline Delivery Mode & $\begin{array}{l}\text { Attended home delivery to } \\
\text { the customers' premises }\end{array}$ \\
\hline Delivery Time & $\begin{array}{l}\text { Delivery within a specific } \\
\text { delivery time slot requested } \\
\text { by the customers }\end{array}$ \\
\hline Delivery Area & $\begin{array}{l}\text { Regional deliveries within } \\
\text { an urban area }\end{array}$ \\
\hline Returns & $\begin{array}{l}\text { No return shipments are } \\
\text { accepted }\end{array}$ \\
\hline
\end{tabular}

The corresponding routing problem is modeled on a weighted complete graph. A formulation as a pick-up and delivery problem was selected to enable the investigation of both dynamic and static settings, i.e. where information on customer orders is revealed over time or known beforehand respectively. The vertex set consists of a central vehicle depot, customer locations, which represent delivery points, and stores as potential pickup locations of FFVs. Arcs denote the shortest path between each point and are assigned with a travel distance and duration. At the start of the simulation experiments, the e-grocery provider defines a service offer stating the delivery day, the width of the time window, potential discounts as well as a delivery fee and guaranteed remaining shelf lives in days for FFVs.

In the following step, a full week of operations is simulated. At random points during the simulation horizon, based on inputted demand patterns, customer demand occurs. At this point the customer compares the service offer with the individual utility function. If the offer is accepted, a shipment is placed. Each shipment is defined by a delivery day, a specific time window and guaranteed remaining shelf lives of the ordered FFVs at final delivery. Each shipment can be fulfilled from any feasible location where the requested products are present. Therefore, the inventory of each store is modeled with the quality development of FFVs estimated based on the duration and storage temperatures of a product while waiting at stores or being transported onboard a vehicle.

Given multiple homogenous capacitated vehicles located at a depot, vehicles routes have to be derived specifying from which pickup point a shipment is collected and at what time and within which route the products are delivered to the customers. 


\section{Measurement of customer preferences}

Instead of assuming a distribution of customer utilities based on published literature, the authors decided to conduct a conjoint study to reveal customer preferences regarding various logistic parameters for the city of Vienna. There are two reasons for this decision. First, literature on consumer preferences for e-grocery is on a too general level to derive parameters for the simulation. Second, the estimation of real-world parameters for the demand side is intended to further foster the validity of the simulation.

Table 2. Attributes and levels for the choicebased conjoint analysis

\begin{tabular}{|l|l|}
\hline Attribute & \multicolumn{1}{|c|}{ Levels } \\
\hline Remaining & Not available \\
shelf life & 1 day \\
& 2 days \\
& 3 days \\
& 4 days \\
& 5 days \\
\hline Delivery day & 0 (same day delivery) \\
& 1 (next day delivery) \\
& 2 days \\
& 3 days \\
\hline Time window & 0 hours (exact time delivery) \\
width & 2 hours \\
& 4 hours \\
& 6 hours \\
& 8 hours \\
\hline Delay of & 0 minutes \\
delivery & 15 minutes \\
& 30 minutes \\
& 45 minutes \\
& 60 minutes \\
\hline Discount & $0 \%$ \\
& $5 \%$ \\
& $10 \%$ \\
& $15 \%$ \\
& $20 \%$ \\
\hline Delivery fee & 0 EURO \\
& 1.99 EURO \\
& 3.99 EURO \\
& 5.99 EURO \\
& 7.99 EURO \\
& 9.99 EURO \\
& \\
\hline
\end{tabular}

From the viewpoint of a customer, e-grocery differs from traditional retailing by various logistic attributes. We, therefore, develop a choice-based conjoint analysis that simulates a typical grocery purchase decision that contains FFVs. Our approach is comparable to $[13,14]$ but lays its focus on a more fine-grained definition of logistics attributes [15]. Table 2 contains the attributes and levels used to describe the offer.

For data collection, a total number of 531 respondents were recruited. To achieve representability for the city of Vienna, a stratified sample was used. We use age, gender and residential area as strata. The interviews were conducted online and administered together with a professional third party panel provider. Beside 5 conjoint tasks that each respondent was asked to answer, additional information regarding respondents' characteristics and shopping behavior was collected. A full profile of conjoint tasks was created randomly from the attributes given in Table 2 and the tasks have been randomly assigned to each respondent. Each task consists of a set of two offers. In addition, respondents can also choose the 'non choice' option indicating that the offered alternatives do not match their needs. A sample task is presented in Figure 1.

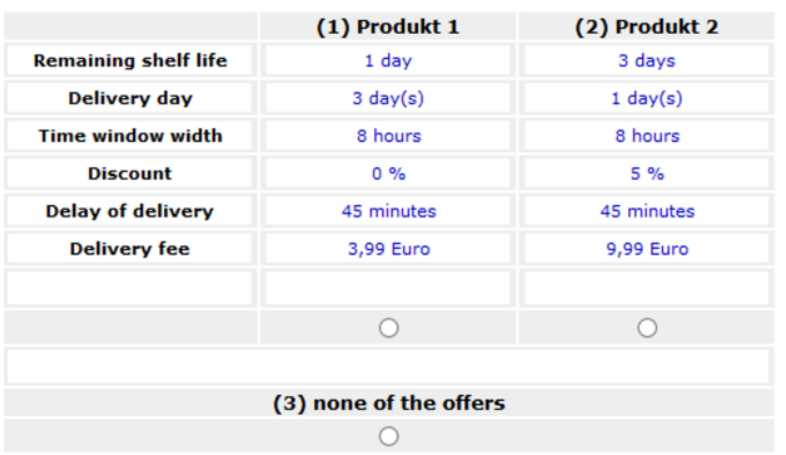

Figure 1. One sample conjoint task

To derive the part-worth utilities of the levels, we estimate a logit-model with consumers' choice as dependent variable and the levels as independent variables. The model was estimated using $R$ [16] and the 'mlogit' package [17]. The respective outcome is given in Table 3. Column 3 gives the utility estimate for the respective levels. Assuming an additive utility model, the part-worth utilities for each attribute add up to the overall utility perception for the customer. In the simulation, consumers will compare the overall utility to the value of the non-choice option to decide if they will place an order. 
Table 3. Parameter estimates for the logit model

\begin{tabular}{|c|c|c|c|c|}
\hline 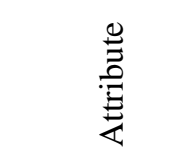 & త্ & 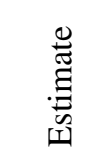 & 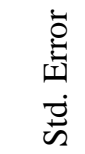 & $\frac{\widehat{I}}{\stackrel{\Delta}{\leftrightarrows}}$ \\
\hline \multirow{5}{*}{$\begin{array}{l}\text { Remaining } \\
\text { shelf life } \\
\text { [days] }\end{array}$} & 1 & 0.21 & 0.12 & 0.07 \\
\hline & 2 & 0.52 & 0.11 & 0.00 \\
\hline & 3 & 0.66 & 0.11 & 0.00 \\
\hline & 4 & 0.67 & 0.11 & 0.00 \\
\hline & 5 & 0.61 & 0.11 & 0.00 \\
\hline \multirow{3}{*}{$\begin{array}{l}\text { Delivery day } \\
\text { [days] }\end{array}$} & 1 & -0.11 & 0.09 & 0.19 \\
\hline & 2 & -0.30 & 0.09 & 0.00 \\
\hline & 3 & -0.44 & 0.09 & 0.00 \\
\hline \multirow{4}{*}{$\begin{array}{l}\text { Time } \\
\text { window } \\
\text { width } \\
\text { [hours] }\end{array}$} & 2 & 0.14 & 0.10 & 0.16 \\
\hline & 4 & -0.08 & 0.10 & 0.40 \\
\hline & 6 & -0.37 & 0.10 & 0.00 \\
\hline & 8 & -0.52 & 0.10 & 0.00 \\
\hline \multirow{4}{*}{$\begin{array}{l}\text { Delay of } \\
\text { delivery } \\
\text { [minutes] }\end{array}$} & 15 & -0.02 & 0.10 & 0.85 \\
\hline & 30 & 0.00 & 0.10 & 0.96 \\
\hline & 45 & -0.26 & 0.10 & 0.01 \\
\hline & 60 & -0.36 & 0.10 & 0.00 \\
\hline \multirow{4}{*}{$\begin{array}{l}\text { Discount } \\
{[\%]}\end{array}$} & 5 & 0.06 & 0.10 & 0.53 \\
\hline & 10 & 0.26 & 0.10 & 0.01 \\
\hline & 15 & 0.29 & 0.10 & 0.00 \\
\hline & 20 & 0.42 & 0.10 & 0.00 \\
\hline \multirow{5}{*}{$\begin{array}{l}\text { Delivery fee } \\
\text { [EURO] }\end{array}$} & 1.99 & -0.33 & 0.10 & 0.00 \\
\hline & 3.99 & -0.55 & 0.10 & 0.00 \\
\hline & 5.99 & -1.06 & 0.10 & 0.00 \\
\hline & 7.99 & -1.57 & 0.11 & 0.00 \\
\hline & 9.99 & -1.71 & 0.11 & 0.00 \\
\hline Non Choice & & -0.67 & 0.16 & 0.00 \\
\hline
\end{tabular}

In addition, respondents were asked to indicate their accepted time-windows for delivery out of twelve time windows of two hours (see Figure 2). On average, respondents selected 2.2 time windows. It can be seen that most respondents prefer to receive their products between $16 \mathrm{~h}$ and $22 \mathrm{~h}$. This poses additional challenges to last-mile delivery of FFVs as, contrary to many other product categories in e-commerce, customers have to be at home to receive the goods.

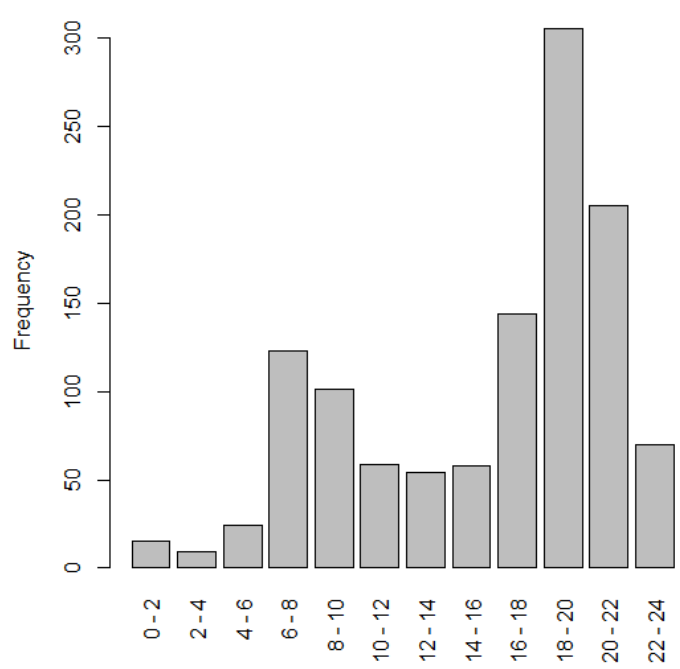

Figure 2. Accepted time windows

Figure 3 presents the accepted days for delivery. It can be seen that customers prefer receiving the goods on weekdays. Delivery on Sunday is only accepted by less than a third of the respondents. On average, each customer names 4.0 days as acceptable for delivery. This further indicates that the requested time windows are harder to meet than the requested delivery days in the planning of the order fulfilment.

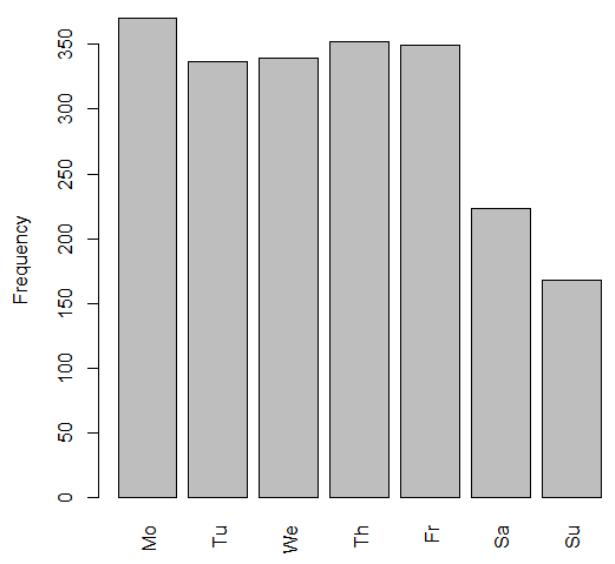

Figure 3. Accepted days for delivery

\section{Decision Support System}

Based on the findings presented in Section 4, the DSS was developed in the subsequent step. It combines an agent-based simulation with heuristic optimization procedures and food quality models. Agent-based 
simulations [18] enable one to randomly generate demand and to model each customer and food product individually based on specified parameters and decision rules. This allows us to directly transfer the measured customer preferences to generate a wide range of diverse customers and further to model each food product individually based on respective storage and transport conditions and durations. Heuristic optimization procedures assign products to orders and route deliveries within the DSS, while food quality models are incorporated to estimate the development of shelf lives of FFVs throughout the study period.

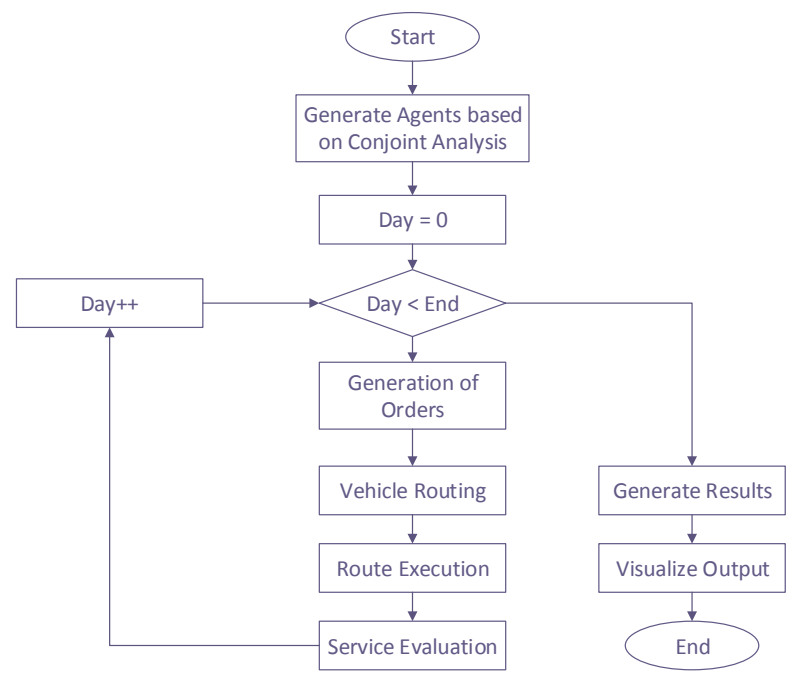

Figure 4. Overview of the DSS structure

Figure 4 provides an overview of steps taken within the DSS. At the start of a single simulation run, customer agents are randomly generated with detailed characteristics derived from the survey results. Furthermore, the transportation network and the provider's inventories at each store are initialized. For each day in the simulation horizon, orders are generated. Therefore, the service offered by the egrocery provider is evaluated by each individual agent and, if accepted, an order is generated. These orders are subsequently assigned to specific products and vehicle routes. At each delivery of products to customers, the performance of the shipment is evaluated against the individual agent preferences. After all days are simulated, aggregated results are generated and visualized to the user.

The following subsections briefly introduce the individual components of the DSS.

\subsection{Agent Generation}

Five different agent classes are modeled within the DSS to simulate e-grocery operations, namely locations, products, customers, shipments and vehicles.

Locations, which are defined by geographic coordinates, present points of interest within the simulation such as store locations, demand points and the vehicle depot. In case of a store, the location is further initialized with an inventory consisting of multiple product agents.

These agents are used to model the quality of food products over time based on the generic shelf life model presented in [19], which enables the consideration of about 60 FFVs within the DSS. While multiple attributes influence the quality of a FFV, e.g., firmness, weight loss, taste, visual appearance, in many cases, a single attribute is mainly influencing the shelf life. Consequently, the model is based on an expected shelf life in days as well as a spoilage rate $\left(\mathrm{k}_{\mathrm{ref}}\right)$ at a reference temperature $\left(\mathrm{T}_{\text {ref }}\right)$. Considering Arrhenius equation [20], spoilage rates of FFVs (k) decrease more at higher temperatures and less at lower ones $\left(\mathrm{T}_{\mathrm{abs}}\right)$ based on the energy of activation (EA) and a gas constant (R) of the FFV as shown in Equation 1.

$$
k=k_{r e f} e^{\frac{E A}{R}\left(\frac{1}{T_{r e f}}-\frac{1}{T_{a b s}}\right)}
$$

Linear kinetics are assumed in our implementation. Therefore, the user defines a quality limit at which the products can no longer be sold. As shown in Equation 2 , the remaining shelf life in days (KQ), is calculated by dividing the difference between the current quality $\left(\mathrm{Q}_{0}\right)$ and the limit $\left(\mathrm{Q}_{1}\right)$ by the spoilage rate per day $(\mathrm{k})$.

$$
K Q=\frac{Q_{0}-Q_{l}}{k}
$$

If the quality deteriorates below the defined quality limit, the product is marked as food waste and removed from the inventory, however, if it is already in delivery, the product is still shipped to the customer.

Customers are initialized based on the output data of the conjoint analysis and survey results. Therefore, each survey response concerning delivery days and preferred time windows corresponds to a single agent type. Each customer is assigned to a location agent in the study area and a response type. Additionally, the utility parameters of the conjoint analysis are set based on a normal distribution given by parameters estimated in Table 3. Each customer agent may request one or more shipments during the simulation period. A shipment is initialized with a list of potential stores from which the shipment can be served based on current inventory levels. Additionally, the shipment saves the final delivery location and additional delivery requirements such as the guaranteed remaining shelf life at delivery and the delivery time window. 
To deliver such shipments, vehicles agents model movements and the loading as well as final delivery of shipments to end customers. Each vehicle starts and ends its tour at a depot operated by the e-grocery provider. On a day of operations, the vehicle picks up and delivers multiple products based on the calculated vehicle route and driving durations. During transport and loading operations, food quality is updated based on the respective storage temperatures and durations.

\subsection{Generation of Orders}

When a demand for e-groceries occurs, the customer visits the provider's online store. The order is presented to the customer and evaluated with the customers' utility function. If the offer is sufficient, i.e. the perceived value is higher than the non-choice option, an order is placed. In such a case, a shipment agent is generated and assigned to a randomly selected time window out of the list of potential times for this customer.

\subsection{Vehicle Routing and Route Execution}

At a user-defined scheduling interval, e.g., each day, all open shipments which have to be delivered before the start of the following interval are scheduled. Therefore, the decisions with which product from which store an order should be fulfilled as well as the delivery vehicle, route and time need to be set. As the vehicle routing procedure is called at multiple times during a single simulation run and the DSS is designed to study both dynamic same-day delivery problems and static problems, a focus on deriving vehicle routing solutions in real-time was set. Consequently, a combination of a best insertion heuristic [21] and local search neighborhood operators is employed.

Therefore, in a first step, each open shipment is sequentially inserted at the most promising vehicle route position. All potential pickup locations, i.e. stores where the requested product is available, are evaluated as well as all feasible combination of pickup and delivery positions. To consider from which store a shipment potentially can be picked up, the procedure checks if the requested FFVs are available for shipment at the given location. Therefore, a firstexpired-first-out (FEFO) inventory strategy is implemented, i.e. to minimize food losses, the products which are expected to expire the earliest are shipped first. Consequently, the routing procedure is provided with a list of candidate pickup locations for each shipment. Subsequently, all options are evaluated starting with the one closest to the location of the customer requesting the products. The option resulting in the lowest objective value is scheduled.
After all new shipments are inserted to a vehicle, a local search procedure is run to improve the solution quality. It checks relocating each shipment to any other position within the current or on any other vehicle route. Additionally, the option to alter the pickup location and selected product assigned to the shipment is further evaluated. In case an improvement is found, the changes are scheduled and the procedures are repeated until no further improvements are found. At this point, the vehicle routes are fixed and the simulation continues by visualizing vehicle movements and evaluating performed deliveries.

\subsection{Service Evaluation}

At delivery, the provided service in respect to a violation of the set time window and the specific food quality of products is evaluated against the offer presented to the customer at the time of the order. Late deliveries occur if the available vehicles are not able to fulfill all requests on time, i.e. they are over-utilized, while deviation in the expected food quality result if the stock of the e-grocery provider does not match the orders concerning quantity and quality requirements of the FFVs. For service evaluation, the attributes and results given in Tables 2 and 3 are used. Delays as well as insufficient shelf lives are evaluated with the subsequent level by quality, i.e. for a delay of 7 minutes, the value of a delay of 15 minutes is taken, while a shelf life of 2.3 days is evaluated with the 2 day level value of the specific customer agent. The perceived utility of each shipment is saved and, at the end of the simulation run, reported to the user compared against the expected utility at time of order.

\section{Computational Experiments}

The DSS was developed with the simulation software AnyLogic 8.0.5 [22] with routing procedures coded in Java. Travel distances and durations between various locations are calculated by facilitating GraphHopper 0.5 [23] with real-world street network data based on OpenStreetMap [24].

To test the DSS and to derive implications, a test setting based on an omni-channel grocery provider in Vienna, Austria, is generated. The provider operates 255 stores throughout the city from which e-grocery orders can be fulfilled. For delivery, five vehicles located at a depot in the south of the city are assumed. To locate customer orders and to limit the problem size, customers are grouped in zones generated from the 1,525 electoral districts of the city [25]. The demand area was limited to highly populated districts in the center of the city. In each of these zones, 
customer agents are initialized from the population figures, i.e. zones with a higher population generate more demand. Orders are further grouped by households assuming an average household size of 2.01 for the study region [26], resulting in approximately 150,000 households within the demand area. To simulate the demand volume, a total market share of $1 \%$ for e-groceries is assumed [27]. Of these orders, $15 \%$ are placed with the investigated provider. This results in approximately 600 customer requests per week based on the shopping data derived from the customer survey.

Figure 5 plots the study region and indicates the locations of stores as well as of the vehicle depot.

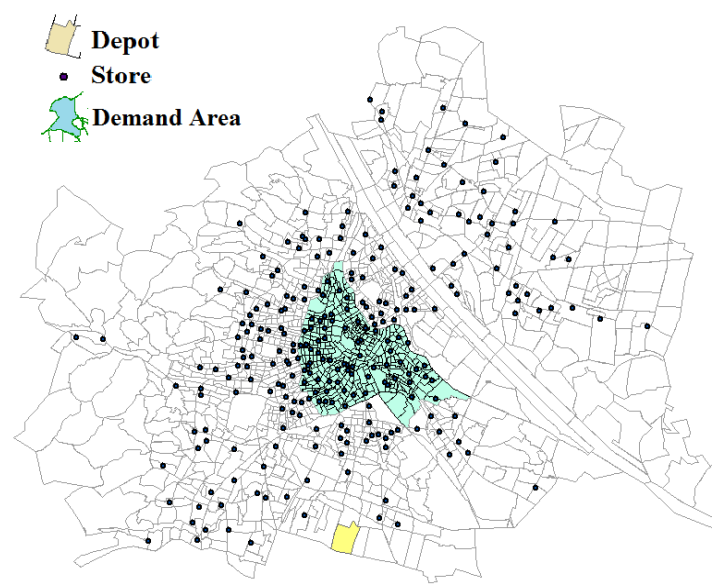

Figure 5. Study area

As a sample setting, the shipment of strawberries to customers is considered. Strawberries are characterized with high sale volumes and short shelf lives and, consequently, are of particular interest to e-grocery logistics operations. To simulate the development of each individual product, i.e. a package of strawberries, over time, parameters and standard errors published in [28] are taken assuming an expected shelf life of approximately 5.5 days for a package of strawberries. Within the DSS, for each individual product, the energy of activation, initial quality as well as the maximum shelf life at the reference temperatures are drawn from a normal distribution. Storage temperatures are set at $4^{\circ} \mathrm{C}$ and $10^{\circ} \mathrm{C}$ within vehicles and at stores respectively. Available products are based on an expected order quantity of $85 \mathrm{FFVs}$ per day and a desired service level of $95 \%$. Each product is assigned to a uniformly randomly selected store and initiated with a random initial quality between $90 \%$ and $100 \%$ of the maximum shelf life of the product. Each day within the simulation horizon, inventory is replenished.

Table 4 specifies the considered service offered by the e-grocery provider to its customers within the computational experiments. A week of operations is analyzed with shipments being delivered to customers between 8 a.m. and 8 p.m. Based on the survey results, all generated shipments are distributed to a specific weekday and time window of two hours. Shipments are delivered on the day following the order. The guaranteed remaining shelf life will be varied within the computational experiments between 1 and 5 days. A delivery fee of $€ 3.99$ is charged and no discount on e-grocery orders is given.

To consider stochasticity, each simulation settings is run with 100 replications and average results are reported.

Table 4. Investigated setting of the DSS within the computational experiments

\begin{tabular}{|l|c|}
\hline Parameter & Value \\
\hline Simulation Period & 1 Week \\
\hline Delivery Time & $08: 00-20: 00$ \\
\hline Time Window Width & 2 hours \\
\hline Delivery Day & Next day delivery \\
\hline Guaranteed Shelf Life & 1 to 5 days \\
\hline Delivery Fee & $€ 3.99$ \\
\hline Discount & $0 \%$ \\
\hline
\end{tabular}

\section{Preliminary Results and Discussion}

Table 5 states preliminary results of the performed computational experiments to investigate the impact of offering guaranteed shelf lives for FFV on order volume and customer utility.

Table 5. Impact of guaranteeing remaining shelf lives of FFVs

\begin{tabular}{|l|r|r|r|r|}
\hline $\begin{array}{l}\text { Days } \\
\text { FFVs }\end{array}$ & $\begin{array}{c}\text { Delivered } \\
\text { Orders }\end{array}$ & \multicolumn{1}{c|}{$\begin{array}{c}\text { Stock- } \\
\text { outs }\end{array}$} & $\begin{array}{c}\text { Expected } \\
\text { Utility }\end{array}$ & $\begin{array}{c}\text { Actual } \\
\text { Utility }\end{array}$ \\
\hline 1 & 467.04 & 2.30 & -128.68 & 64.88 \\
\hline 2 & 517.77 & 5.92 & -4.76 & 58.25 \\
\hline 3 & 523.09 & 7.35 & 71.05 & 58.89 \\
\hline 4 & 523.23 & 14.87 & 75.92 & 56.88 \\
\hline 5 & 521.89 & 101.36 & 45.00 & -1.95 \\
\hline
\end{tabular}

Guaranteeing long remaining shelf lives of FFVs at delivery allows the provider to increase the number of orders. If a high quality is promised, e.g., a remaining shelf life of 5 days, then the provider is, however, not able to include strawberries in each delivery, i.e. stockouts occur, due to the high quality limit. In such cases, the remaining delivery is performed without the food product, resulting in high losses of utility at arrival. A comparison of the utility expected by the customer at order time to the actual utility at delivery further highlights the importance of jointly considering logistics processes and service offers. Promising long 
remaining shelf lives of FFVs to customers potentially requires adjusting operations by enabling faster deliveries or larger inventories to guarantee food quality. Considering the sample setting studied in this work, the provider may offer a remaining shelf life of 3 days with little impact on logistics operations. In case a higher level is required, related parameters such as the given distribution network, storage temperatures along the disruption chain, vehicle fleet sizes or replenishment cycles have to be adjusted.

Additionally, the results indicate that various customers are interested in the service offer, however, do not order due to the restricted delivery times of the e-grocery provider. Particularly, as shown in Figure 2, multiple customers accept orders early in the morning, a time period which is currently not served by the provider. Consequently, in Table 6, the impact of offering a 24-hour delivery service is investigated.

Table 6. Impact of offering 24-hour deliveries

\begin{tabular}{|l|r|r|r|r|}
\hline $\begin{array}{l}\text { Days } \\
\text { FFVs }\end{array}$ & $\begin{array}{c}\text { Delivered } \\
\text { Orders }\end{array}$ & $\begin{array}{c}\text { Stock- } \\
\text { outs }\end{array}$ & $\begin{array}{c}\text { Expected } \\
\text { Utility }\end{array}$ & $\begin{array}{c}\text { Actual } \\
\text { Utility }\end{array}$ \\
\hline 1 & 501.54 & 2.88 & -138.04 & 69.67 \\
\hline 2 & 556.30 & 8.21 & -4.95 & 60.41 \\
\hline 3 & 561.96 & 10.25 & 76.40 & 60.82 \\
\hline 4 & 562.09 & 23.96 & 81.57 & 54.30 \\
\hline 5 & 560.60 & 129.86 & 48.37 & -17.18 \\
\hline
\end{tabular}

In all settings, providing customers a 24-hour delivery service increases sales. Furthermore, it enables providers to reduce demand peaks as multiple customers only accept orders either early in the morning or late in the afternoon, i.e. before or after work. In low shelf life settings, this enables the provider to increase the total utility by fulfilling more customer requests and reducing food losses. At high guaranteed shelf lives, however, the negative impact of stock-outs prevails resulting in a loss of overall utility. By running multiple settings within the DSS, the impact of such a change in delivery times can be investigated considering potential impacts on various related factors such as vehicle utilization, inventory strategies and food losses.

\section{Conclusions}

The quality of e-grocery operations is impacted by both customer preferences and the performance of the last-mile distribution system of the provider. To study such impacts, customer preferences were measured and included in a DSS combining simulation methods with food quality models and optimization procedures. The resulting DSS allows decision-makers to jointly evaluate the influence of altering service offers and logistics processes. Results indicate the importance of considering food quality within the delivery of FFVs and a potential to improve service offers based on better understandings of customer preferences.

Further work focuses on expanding the DSS by integrating customer reactions to the delivery service. Consequently, if a delivery does not meet the given specifications, e.g., due to a late delivery or as the remaining shelf life is worse than stated, customers adjust their evaluation of subsequent offers by the providers. This further provides the option to consider such customer's reactions in the planning of shipments within the routing and scheduling procedures, e.g., by prioritizing certain customer segments. Additionally, integrating related logistics processes such as inventory management and replenishment strategies is of interest to enable decision-makers integrated investigations of customer preferences and e-grocery fulfillment processes.

\section{Acknowledgements}

This work was funded at the University of Natural Resources and Life Sciences, Vienna, by the 'Jubiläumsfonds der Stadt Wien für die Universität für Bodenkultur Wien' (project number 11350).

\section{References}

[1] Nielsen. "The Future of Grocery". Nielsen Glob. ECommerce New Retail Rep., The Nielsen Company, New York, 2015, pp. 1-35.

[2] C.J. Reynolds, J.D. Buckley, P. Weinstein, P., J. Boland. "Are the dietary guidelines for meat, fat, fruit and vegetable consumption appropriate for environmental sustainability? A review of the literature". Nutrients 6, 2014, pp. 2251-2265.

[3] A. Fredriksson, K. Liljestrand. "Capturing food logistics: a literature review and research agenda". Int. J. Logist. Res. Appl. 18, 2015, pp. 16-34.

[4] R. Jedermann, M. Nicometo, I. Uysal, W. Lang. "Reducing food losses by intelligent food logistics". Philos. Trans. A. Math. Phys. Eng. Sci. 372, 2014, 20130302.

[5] M.C.N. Nunes. Color atlas of postharvest quality of fruits and vegetables, 1.ed. Blackwell Publ, Ames, Iowa. June 2008 .

[6] N.A.H. Agatz, M. Fleischmann, J.A.E.E. van Nunen. "Efulfillment and multi-channel distribution - A review", Eur. J. Oper. Res. 187, 2008, pp. 339-356. 
[7] A. Hübner, H. Kuhn, J. Wollenburg, J. "Last mile fulfilment and distribution in omni-channel grocery retailing: A strategic planning framework", Int. J. Retail Distrib. Manag. 44, 2016, pp. 228-247.

[8] W.E. Soto-Silva, E. Nadal-Roig, M.C. González-Araya, L.M. Pla-Aragones. "Operational research models applied to the fresh fruit supply chain". Eur. J. Oper. Res. 251, 2016, pp. 345-355.

[9] S.N. Parragh, K.F. Doerner, R.F. Hartl, R.F. "A survey on pickup and delivery problems - Part I: Transportation between customers and depot". Journal für Betriebswirtschaft 58,2008 , pp. 21-51.

[10] C. Tarantilis, C. Kiranoudis. "A meta-heuristic algorithm for the efficient distribution of perishable foods". J. Food Eng. 50, 2001, pp. 1-9.

[11] B.D. Song, Y.D. Ko. “A vehicle routing problem of both refrigerated- and general-type vehicles for perishable food products delivery”. J. Food Eng. 169, 2016, pp. 61-71.

[12] U. Emeç, B. Çatay, B. Bozkaya. "An Adaptive Large Neighborhood Search for an E-grocery Delivery Routing Problem". Comput. Oper. Res. 69, 2016, pp. 109-125.

[13] M. Wilson-Jeanselme, J. Reynolds, "Understanding shoppers' expectations of online grocery retailing". International Journal of Retail \& Distribution Management, Vol. 34 Issue: 7, 2006, pp.529-540.

[14] M. Wilson-Jeanselme, J. Reynolds, "The advantages of preference-based segmentation: An investigation of online grocery retailing". Journal of Targeting, Measurement and Analysis for Marketing, 14.4, 2006, pp. 297-308.

[15] N. Czapla, "Willigness to pay for logistics services in ecommerce". Masterthesis, WU Wien, 2017.

[16] R. "The R Project for Statistical Computing". URL https://www.r-project.org/ (accessed 13.06.17).

[17] Y. Croissant. "Estimation of multinomial logit models in R: The mlogit package". URL http://cran.r- project.org/web/packages/mlogit/vignettes/mlogit.pdf (accessed 13.06.17).

[18] C.M. Macal. "Everything you need to know about agentbased modelling and simulation". J. Simulat 10(2), 2016, pp. 144-156.

[19] L.M.M. Tijskens, J.J Polderdijk, J.J. "A generic model for keeping quality of vegetable produce during storage and distribution". Agric. Syst. 51, 1996, pp. 431-452.

[20] K.J. Laidler. "The development of the Arrhenius equation". J. Chem. Educ 61, 1984, p. 494.

[21] A.M. Campbell, M. Savelsbergh. "Efficient insertion heuristics for vehicle routing and scheduling problems". Transport. Sci 38(3), 2004, pp. 369-378.

[22] AnyLogic. "Anylogic - multimethod simulation software". URL www.anylogic.com/ (accessed 23.05.17).

[23] GraphHopper. "Graphhopper route planner". URL https://graphhopper.com/ (accessed 23.05.17).

[24] OpenStreetMap. "Openstreetmap" URL https://www.openstreetmap.org/ (accessed 23.05.17).

[25] Stadt Wien. "Wahlen in Wien: Wahlsprengel [Elections in Vienna: Electorial districts]". data.gv.at, https://www.data.gv.at/katalog/dataset/79c1030d-5cf6-4d58ade6-02f66fb4dffb (accessed 23.05.17).

[26] Statistik Austria. "Privathaushalte nach Geburtsland der Haushaltsreferenzperson, Haushaltsgröße und Bundesländern - Jahresdurchschnitt 2016 [Privat households by country of origin, size and region - Averages of 2016]". https://www.statistik.at/web_de/statistiken/menschen_und_ge sellschaft/bevoelkerung/haushalte_familien_lebensformen/ha ushalte/023303.html (accessed 23.05.17).

[27] E. Gittenberger, B. Vogl. "Internet-Einzelhandel 2014 [E-Commerce 2014]". WKO - Austrian Economic Chambers, Vienna, Austria.

[28] R.E. Schouten, D. Kessler, L. Orcaray, L., O. van Kooten, O. "Predictability of keeping quality of strawberry batches". Postharvest Biol. Technol. 26, 2002, pp. 35-47. 